\title{
DEVELOPING OF CONSTRUCTION CONTRACTING SECTOR PERFORMANCE IN YEMEN
}

\section{(Received June 30, 2011 Accepted August 14, 2011)}

The construction industry is considered one of the potential contributors to social and economic development in Yemen. The contracting sector, one of construction industry's components, faces major challenges in organizational, technical and financial matters affecting its ability to meet the requirements for implementing strategic projects. This paper presents suggestions and recommendations for developing this sector and increasing its capabilities to overcome such challenges. The presented suggestions \& recommendations were reached based on studying a construction of an international football stadium in Zingobar city of Abian governorate-Yemen as a good practice as well as performance of contractors in other projects and government planning for strategic projects.

\section{تطور أداء قطاع مقاولات الاتشاءات في اليمن}

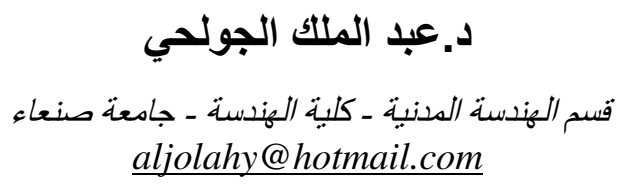

ملخص

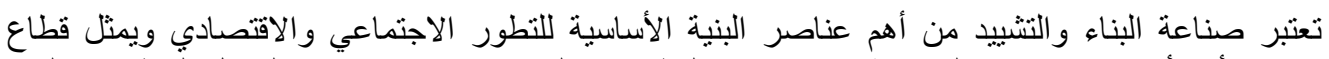

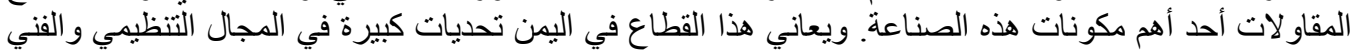

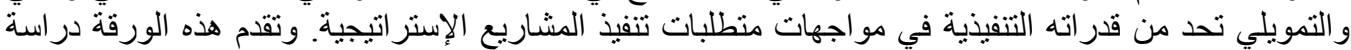

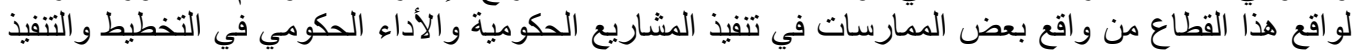

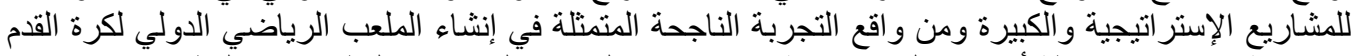

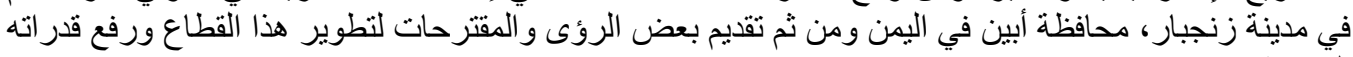

التنفيذية.

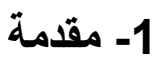

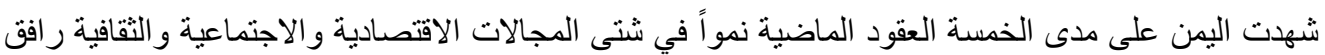

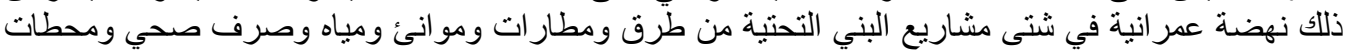

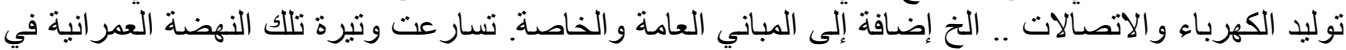

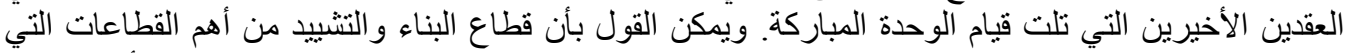

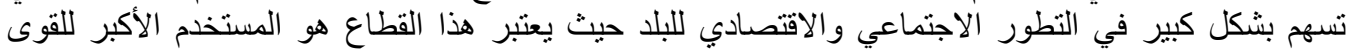

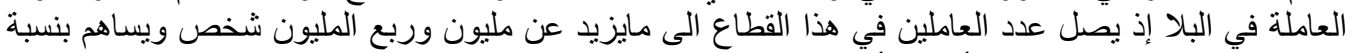

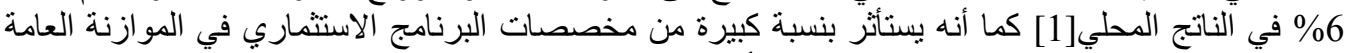

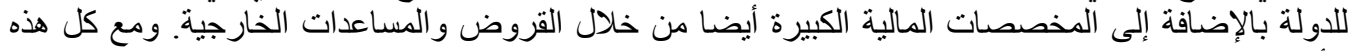

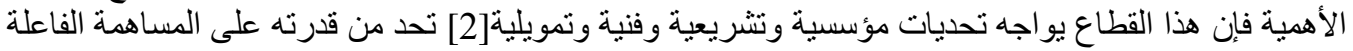

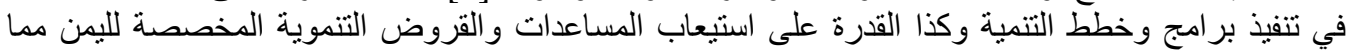


يتطلب من الحكومة تدخلاً مباثراً وفورياً لدراسة المعوقات التي يواجهها هذا القطاع و والعمل على إيجاد الحلول

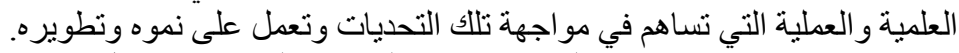

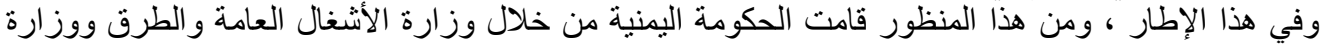

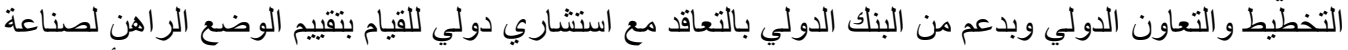
البناء و التثبيد في اليمن من خلال إعداد دراسة تحليلية للوضع الرالي الهن للقطاع حيث تضمنت المسودة الأولية لهذه

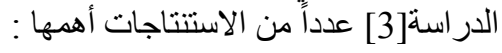

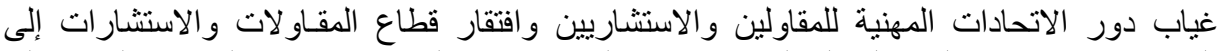

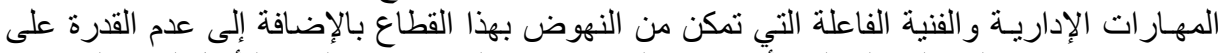

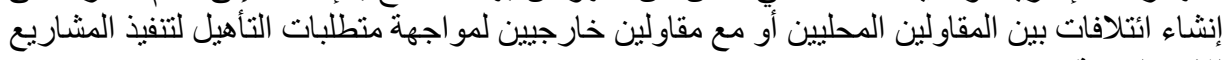

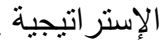
وجود قصور في إعداد الخطط والبرامج لتنفيذ المشاريع مع ضعف القدرة الفنية في مجال إعداد

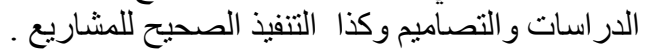
ويوازي ذلك الك

قصور حكومي في التخطيط لأولوية تنفيذ المشاريع وتوفير الاعتمادات المالية اللازمة لتنفيذها في

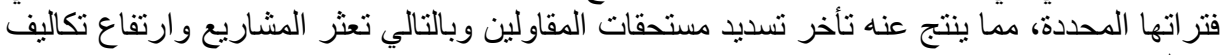
إكمالها . غياب لكودات البناء و المواصفات الفنبة الوطنية.

وبناءُ على الإستنتاجات الدذكورة، أوصت الدراسة المقدمة بمعالجات ضمن خطط قصيرة ومنوسطة وطويلة

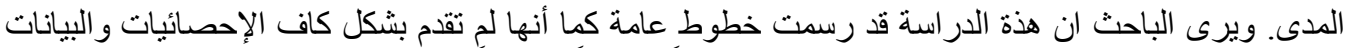

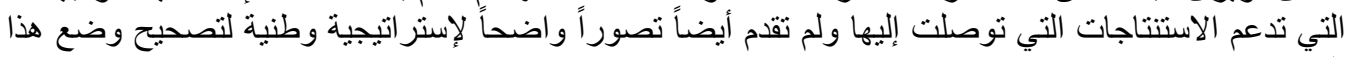
القطاع وتطويره.

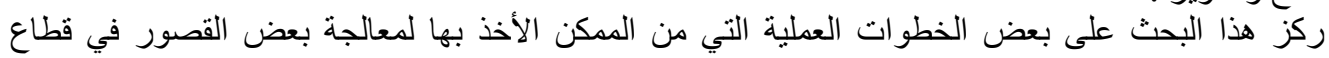

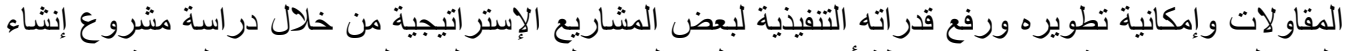

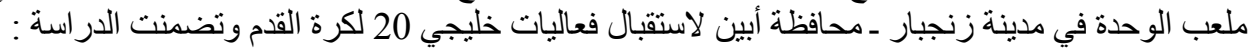

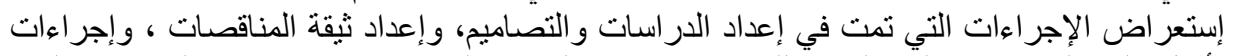
تأهيل المقاولين ، وعملية التنفيذ للمشروع وبيان الإدان العوائد المحققة في عدد من المجالات المات الفنية و الاقتصادية والاجتماعية. معايير التأهيل المطلوبة لثركات المقاولات المتقفمة لتنفيذ المشروع ومدى قدرة المقاولين المحليين (اليمنيين) على الإيفاء بها. الإجراءات المتخذة من قبل ماللك المشروع/ صاحب العمل في تنفيذ المشروع من قبل المقاولين المحليين

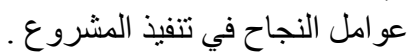

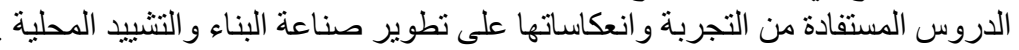

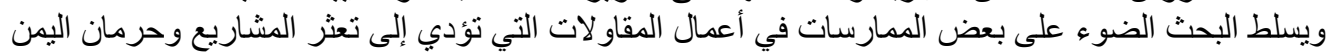

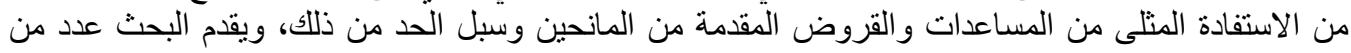

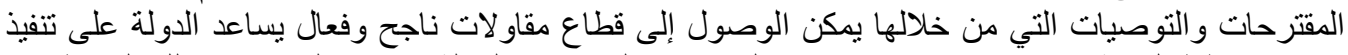

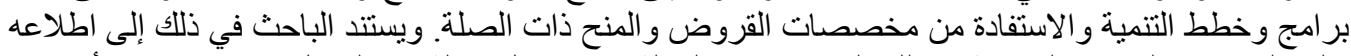

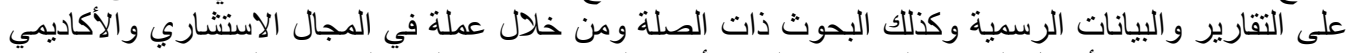
وكقيادي في وزارة الأشغال العامة و الطرق شارك في أعداد الخطط وبر امج التنفيذ لمشاريع الوزارة الإن.

\section{2- إنشاء ملعب الوحدة الرياضي لكرة القدم في مدينة زنجبار ـ محافظة أبين}

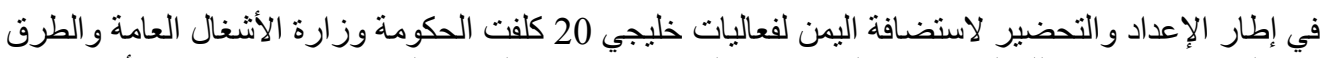

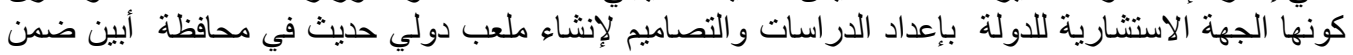
الملاعب الجديدة التي ستستضيف بطوله خليجي 20. 


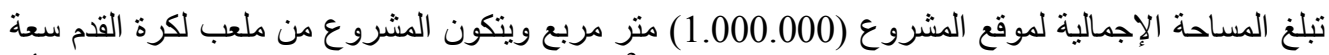

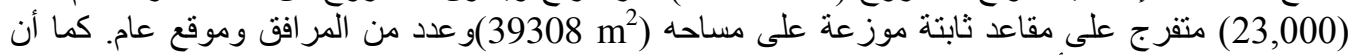

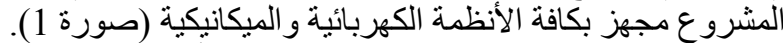

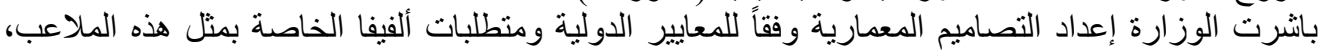

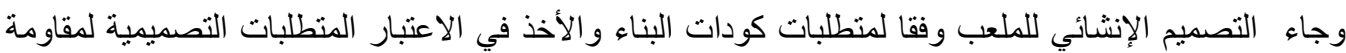

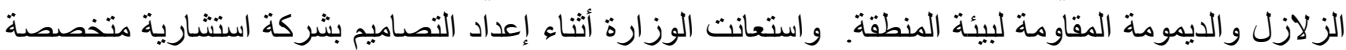

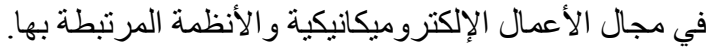

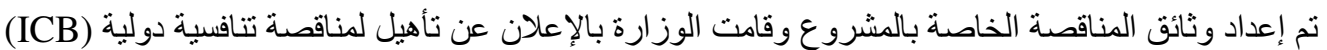

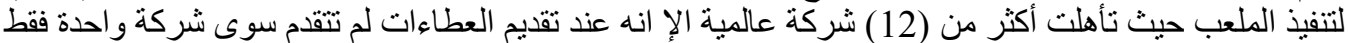

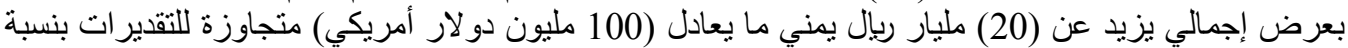

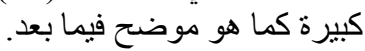

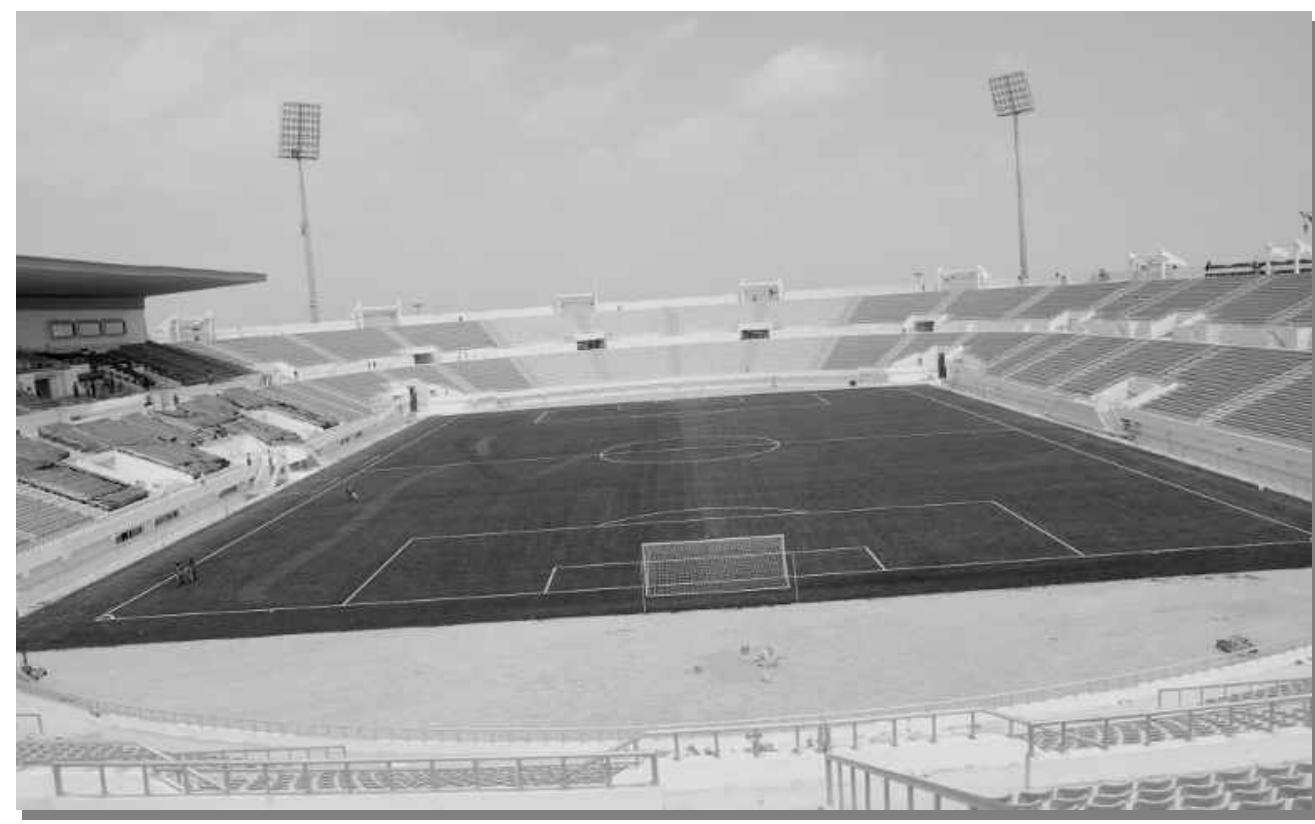

ونظراً لضيق الوقت من حيث تحديد مو عد بدء فعاليات خليجي 20 في مو عد لايتجاوز 22 نوفمبر 2011 قامت الوزارة في بداية العام 2009 باتخاذ عدد من الإجر اءعات لتنفيذ التفيذ المشروع في حدود التكلفة التقديرية (12) مليار

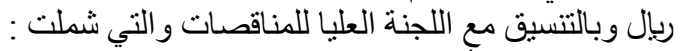
1. تقسيم أعمال المشروع إلى عدد من الحزم ( الحقائب ) بحيث بمكن توزيعها بين عدة مقاولين محليين

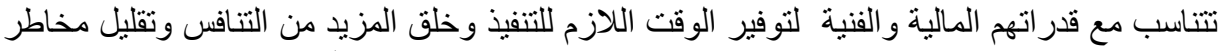

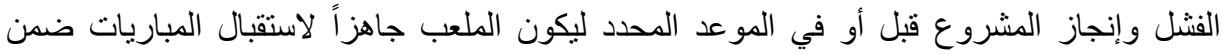

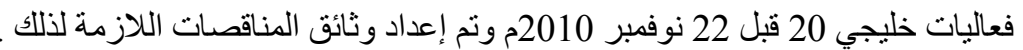

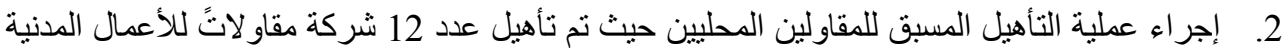

و عدد 21شركة متخصصة في الأعمال الإلكتروميكانيكيةً.

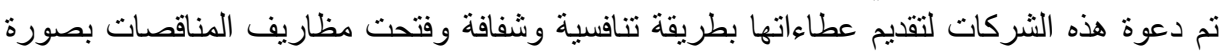

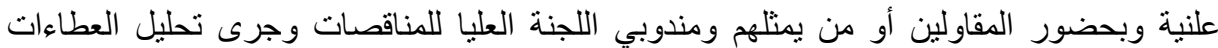

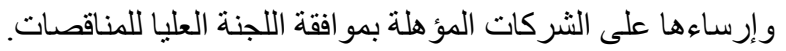

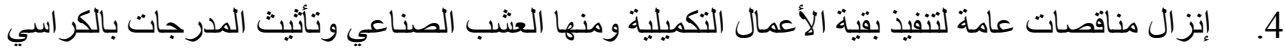

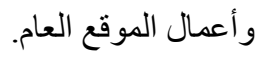


وحيث أن عامل الزمن الدذكور انفاً كان أحد أهم العوامل الرئيسية لتحقيق هدف بدء فعاليات خليجي 20 في

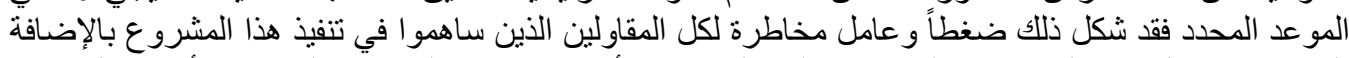

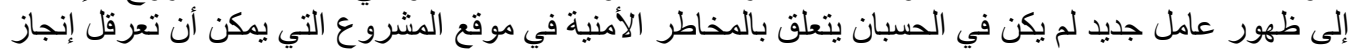

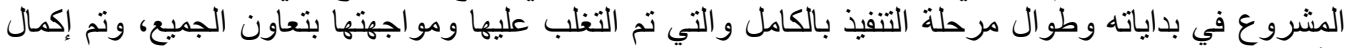

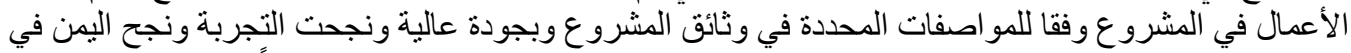

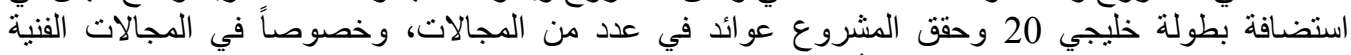
و الإقتصادية و الإجنماعية كما يتبين فيما يأتي.

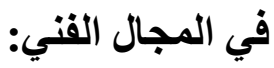

تجربة جديدة في تجزئة أعمال المشاريع الكبيرة التي لا يمتلك المقاول المحلي مؤهلات تنفيذها، وجعلها مناسبة لإمكانيات وقدرات المقاونة المقالين المحليين. تكوين ما يشبه ائتلاف من المقاولين المحليين لتنفيذ أعمال الملعب عن طريق عقود منفصلة لمكونات الملعب. إكساب المقاول اليمني خبرة في مجال أعمال الملاعب وكذلك القدرة على تنفيذ أعمال العقد في فترة زمنية محددة. رفع كفاءة المقاول اليمني في التخطيط و البرمجة لتنفيذ مشاريع نو عية في فنرات زمنية محددة غير قابلة لألتأخير. إكساب الاستثاري اليمني/الدهندس اليمني خبرة في إدارة العقود و أعمال الإشراف والتتسيق بين عدد من المقاولين المنففنين في موقع واحد.

\section{في المجالين الاجتماعي والاقتصادي:}

إثر اك ابناء المنطقة في فعاليات تتفيذ المشروع واستفادتهم بثكل اكبر مقارنة بما كانت ستقوم بة أي

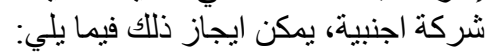

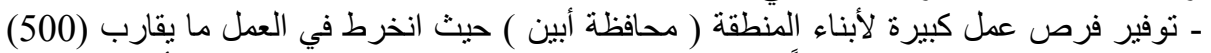

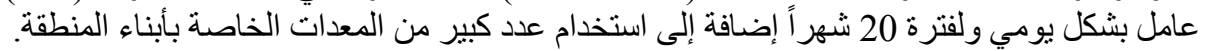

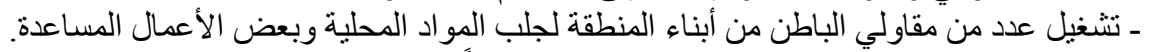

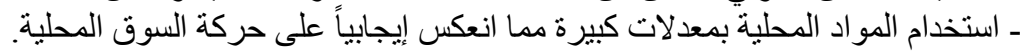
توفير مبالغ مالية كبيرة وصلت إلى حدود(10) مليار ريال بين السعر المقدم من الثركة الأجنبية

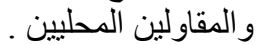
توفير مبالغ مالية كبيرة كنتيجة عن قيمة التعويضات التي كان سيتقام بها المقاول الأجنبي لأسباب

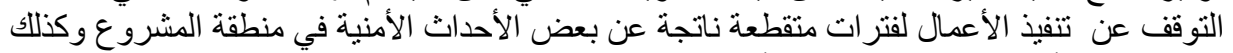

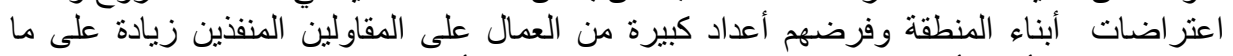

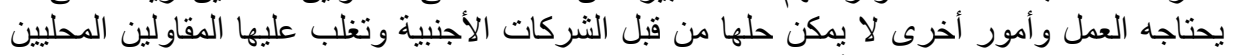
لمعر فتهم بطبيعة المنطقة وثقافة أبنائها.

\section{3- تقييم تجربة إنشاء الملعب وأثرها على تطور قطاع المقاولات}

تعاني صناعة المقاو لات تحديات كبيرة أبرزها ضعف القدرات التنفيذية لشركات المقاو لات المحلية في مو اجهة

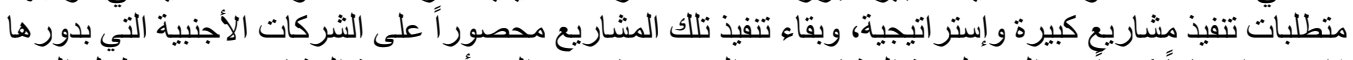

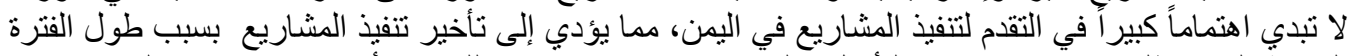

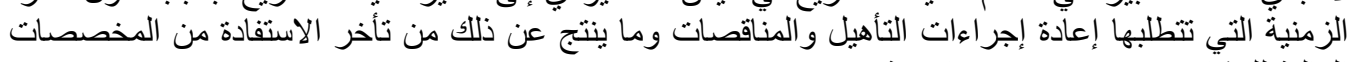

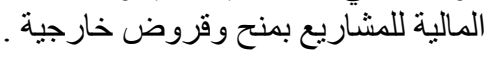


ويمثل إنشاء ملعب الوحدة في أبين حالة واقعية لبروز هذا النوع من التحدي، مما يتطلب الوقوف على هلى هذه الحالة

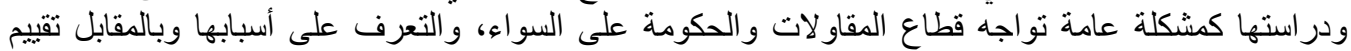

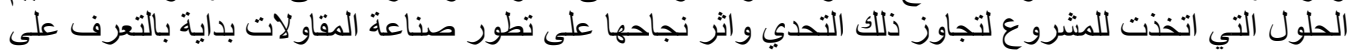

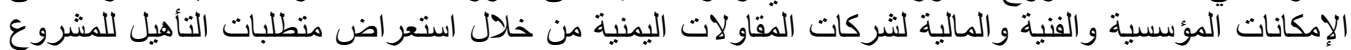

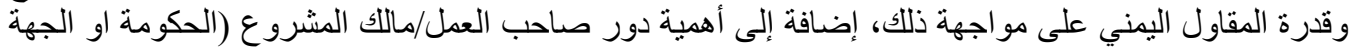

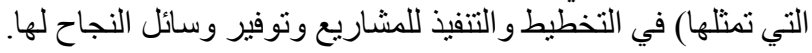

\section{3-1-1}

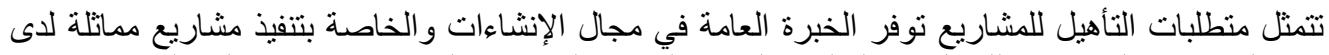

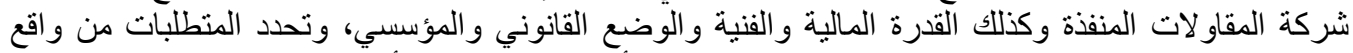

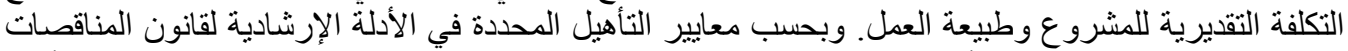

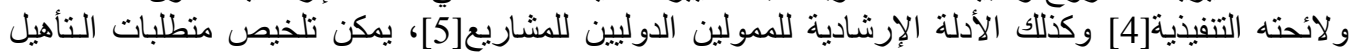

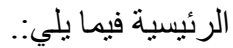

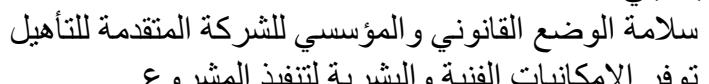

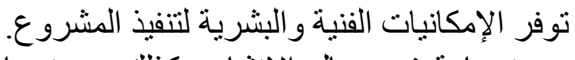

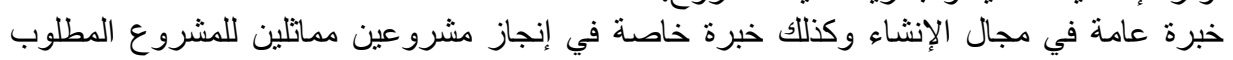

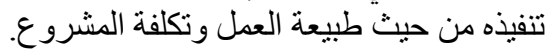

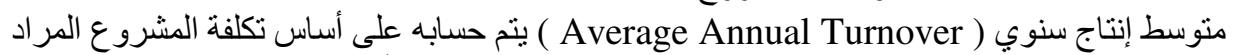
تنفيذه والفترة الزمنية للتنفيذ، وقد تم تحديد مبلغ 50 مليون دولار أمريكي (10 مليار ربإل يمنى) لشركات المقاو لات المتقدمة للتأهل لملعب أبين.

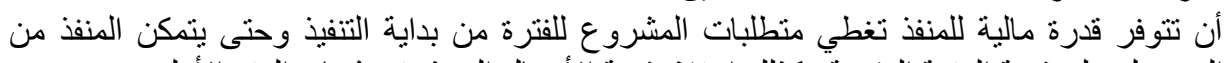

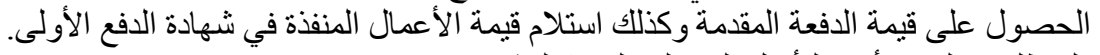

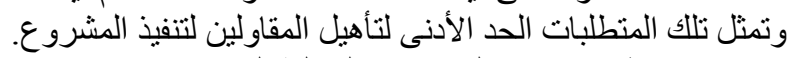

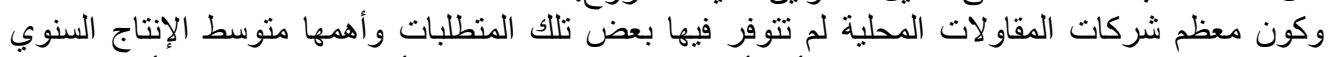

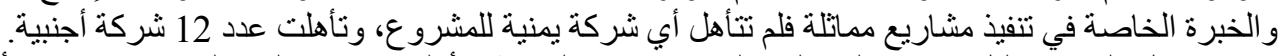

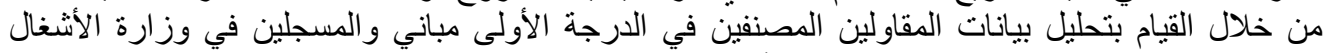

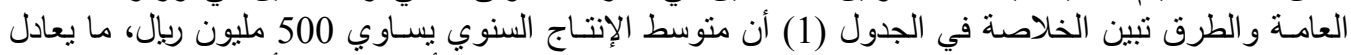

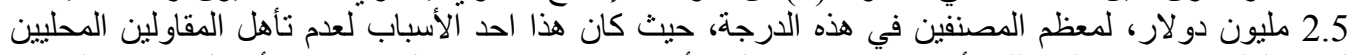

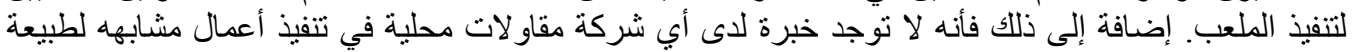

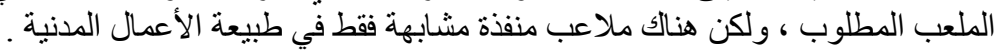

جدول (1) متوسط الإنتاج السنوي لشركات المقاولات اليمنية المصنفة في الدرجة الأولى مباني:

\begin{tabular}{|c|c|c|c|c|c|}
\hline \multirow{2}{*}{ المتوسط بالاولار } & \multicolumn{3}{|c|}{ متوسط الإنتاج بالريال (1000) ريال } & \multirow{2}{*}{ عدد الشركات } & \multirow{2}{*}{ م } \\
\hline & المتوسط & إلى & من & & \\
\hline $7,500,000$ & $1,500,000$ & - & - & 1 & 1 \\
\hline $5,000,000$ & $1,000,000$ & $1,100,000$ & 850,000 & 4 & 2 \\
\hline $2,500,000$ & 500,000 & 750,000 & 450,000 & 15 & 3 \\
\hline
\end{tabular}

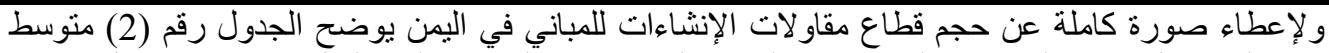

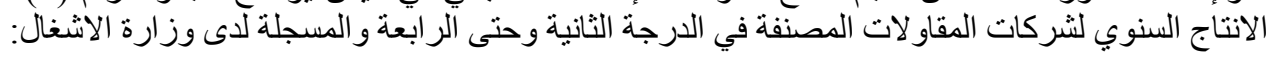


جدول (2) متوسط الإنتاج السنوي لثركات المقاولات المصنفة في الدرجة الثانية ــ الرابعة مباني:

\begin{tabular}{|c|c|c|c|c|c|c|}
\hline \multirow{2}{*}{ المتوسط بالدولار } & \multicolumn{3}{|c|}{ متوسط الإتتاج بالريال (1000) ريال } & \multirow{2}{*}{ عدد الشركات } & \multirow{2}{*}{ 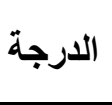 } & \multirow[b]{2}{*}{ ? } \\
\hline & المتوسط & إلى & 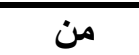 & & & \\
\hline $1,900,000$ & 380,000 & 700,000 & 200,000 & 31 & الثانية & 1 \\
\hline 900,000 & 180,000 & 300,000 & 100,000 & 22 & الثالثة & 2 \\
\hline 450,000 & 90,000 & 160,000 & 40,000 & 23 & الر ابعة & 3 \\
\hline
\end{tabular}

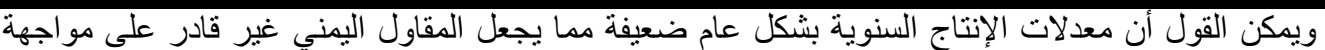

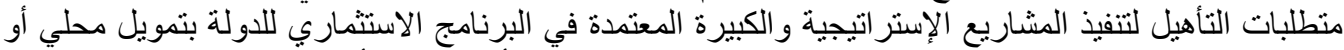
خارجي إضافة إلى محدودية عدد المقاولين ويمكن اعتبار ذللك احد الأسباب في تأخير سحب الئاري المبالغ المخصصة

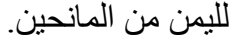

ويرجع تدني معدلات الإنتاج للمقاولين المحليين بشكل عام إلى الأسباب التالية: • أستحو اذ الثركات الأجنيبة على المشاريع الإستر اتيجية والكبيرة التي لالية بستطيع المقاول اليمني مو اجهة

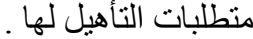

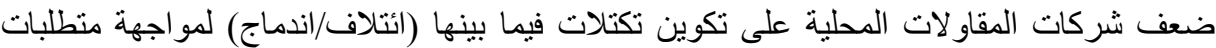

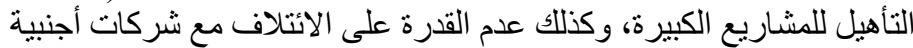

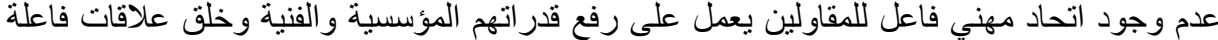

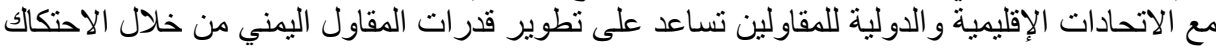

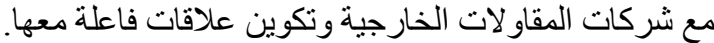

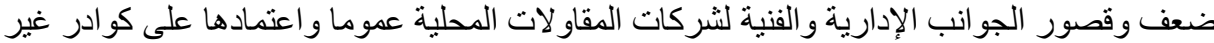
ثابتة سو اء في المجال الفني أو الإداري.

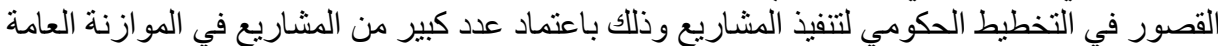

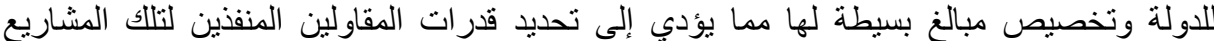

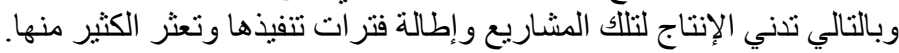

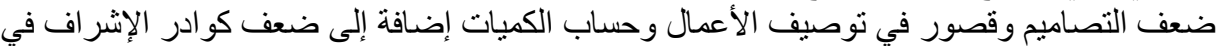

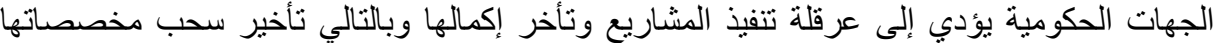

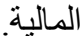

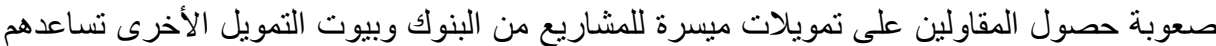

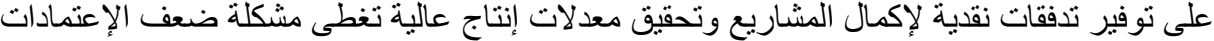
المخصصة في المو ازنة لتلك المشاريع.

\section{3-2 اهتمام الثركات الأجنبية في تنفيذ المشاريع في اليمن}

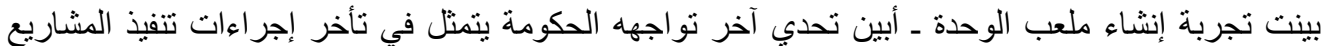

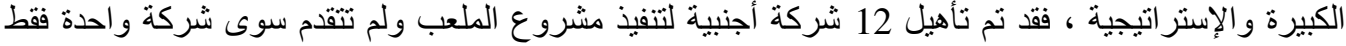

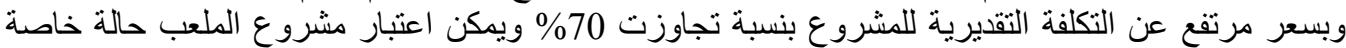

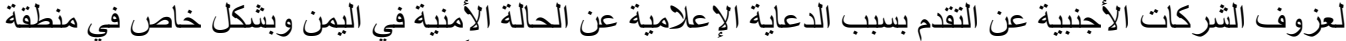

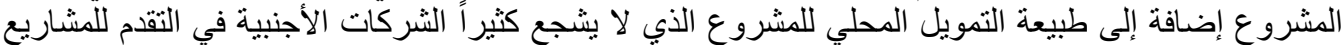
وحتى بعض الثركات المحلية إضافة إلى محدودية الفئل الفترة الزّمنية للتنفيذ.

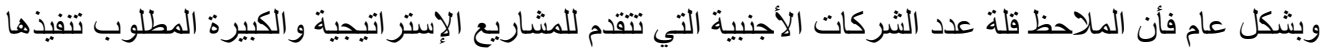

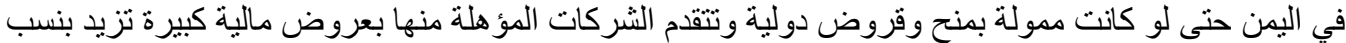

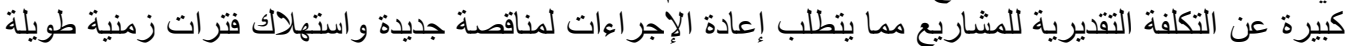

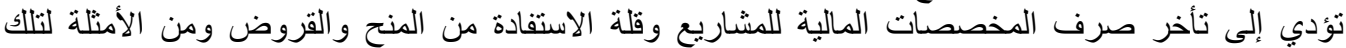
المشاريع المرحلة الثنانية لمطار صنعاء الدولي الذي تصل تكلفته إلى ما يقارب الإن 300 مليون دو لار. 


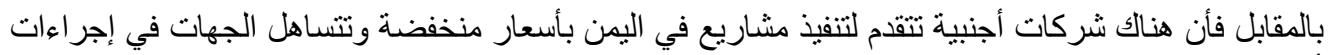

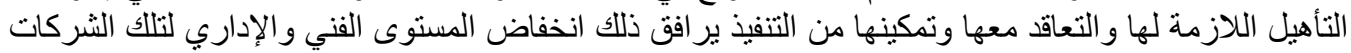

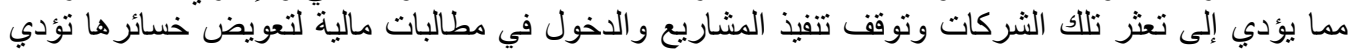

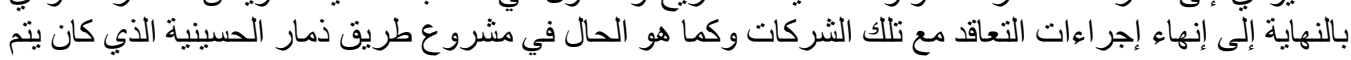

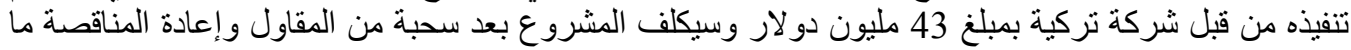

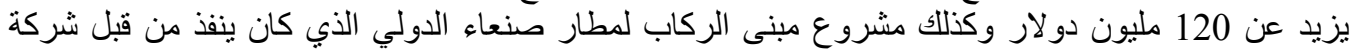

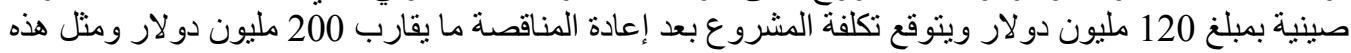

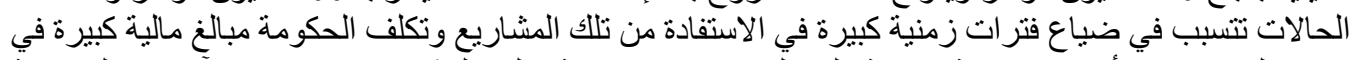

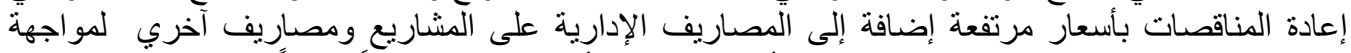

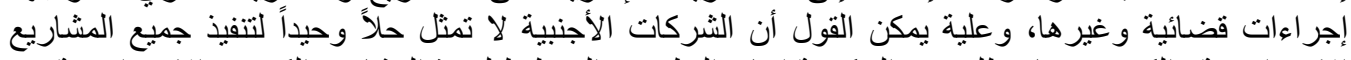

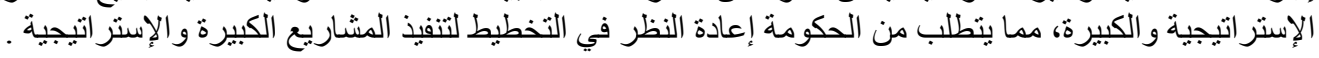

\section{3-3 دور صاحب العمل/ مالك المشروع في التخطيط لتنفيذ المشاريع}

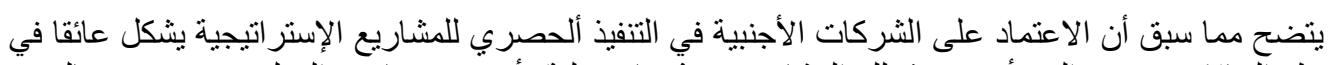

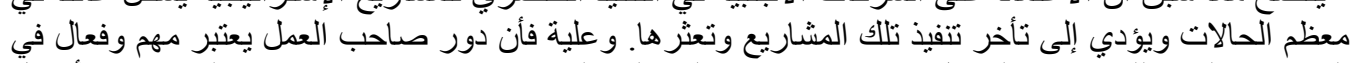

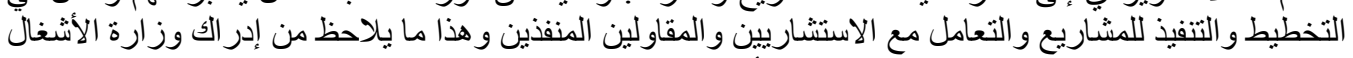

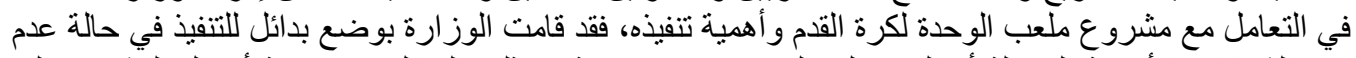

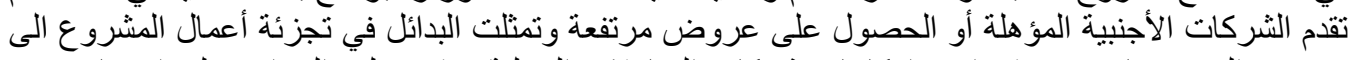

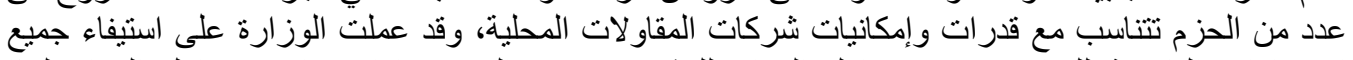

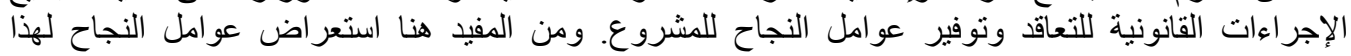

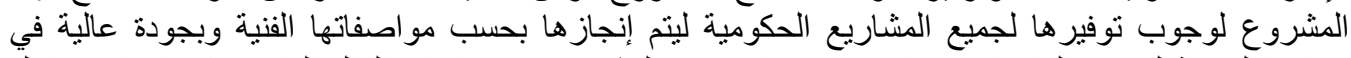

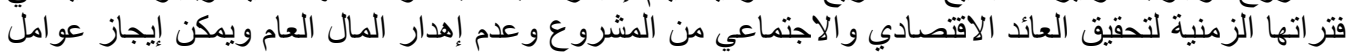
النجاح فيما يلي: إنزية

إعداد الدر اسات و التصاميم للمشروع بشكل متكامل ووفقا لمرجعيات هندسيه وفنية.

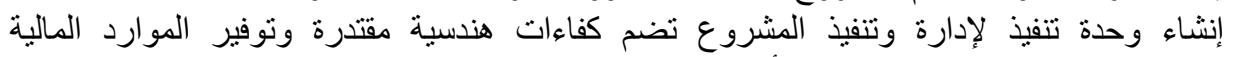

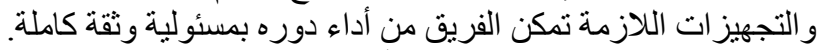

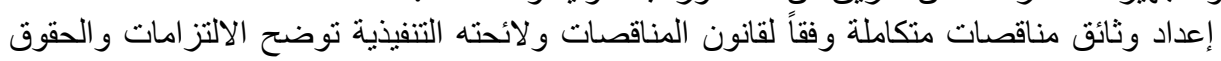

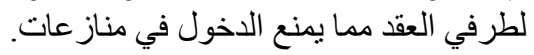

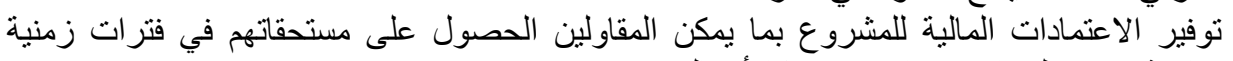

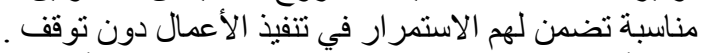

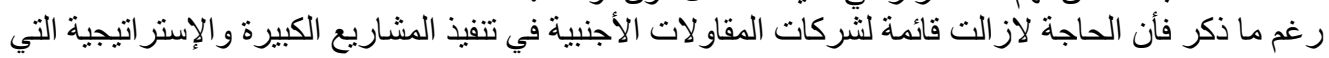

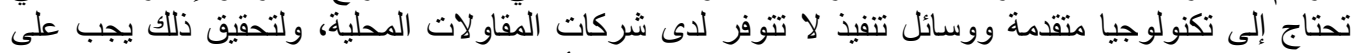

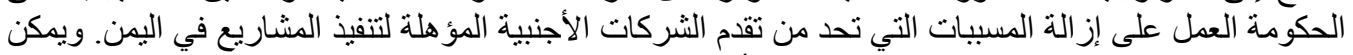

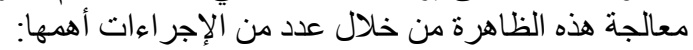
معالجة الإختلالات الأمنية وتحسين البيئة القانونية والفراء القضائية وتنتيط الدور الإعلامي لإبراز دور اليمن في ذلك. تشجيع الائتلافات بين الشركات المقات الملية والأجنبية .

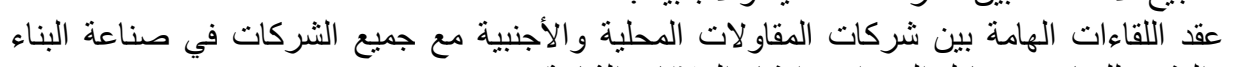

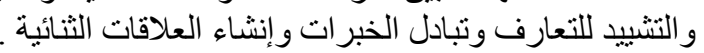

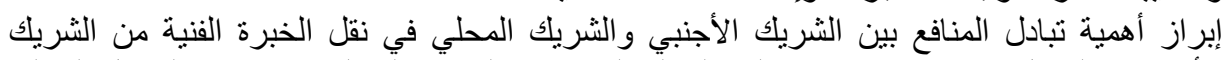

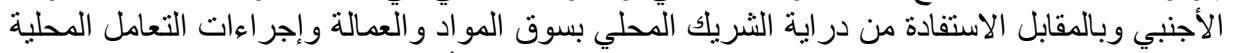

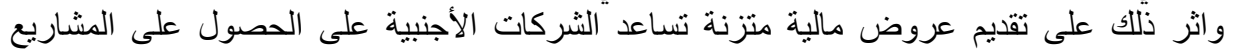
و انجاز ها. ضرورة إسنيفاء الثريك المحلي شروط المقاول بحسب توصيف وزارة الأشغال. 


\section{4- الاروس المستفادة من التجربة ومتطلبات التطبيق}

إن تجربة إنشاء ملعب أبين قد أثبتت نجاحها وبينت قدرة المقاول اليمني على تتفيذ مشاريع استر اتيجيه وكبيرة،

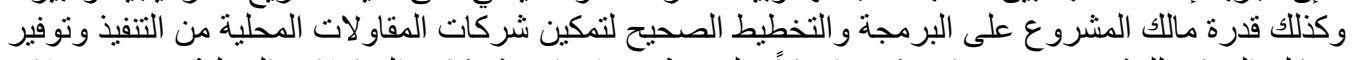

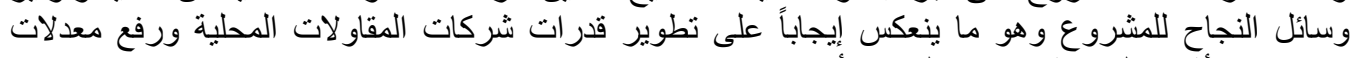

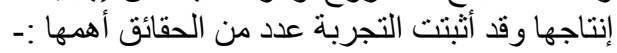

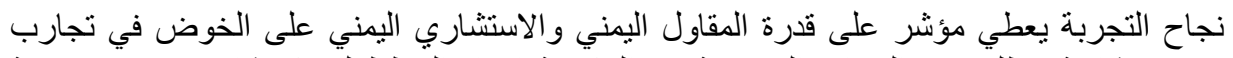

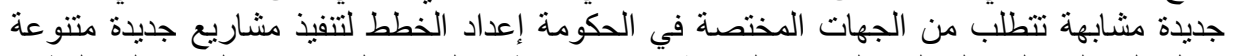
توكل إلى المقاولين المحليين لتعزيز التجربة ومساعدة قطاع البناء والتشبيد في اليمن على اعلى التطور و البقاء . توكن.

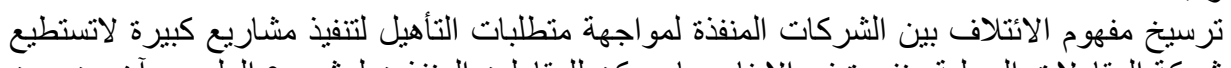

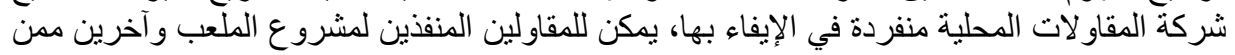

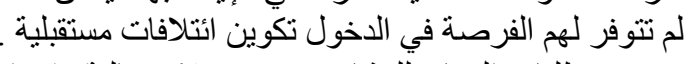

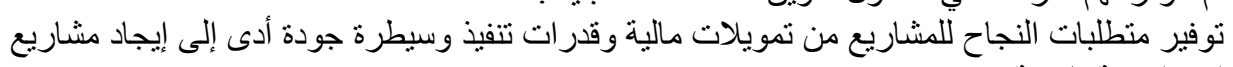

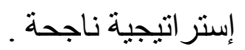
إمكانية تكوين قطاع مقاو لات قوي ناجي ناجح يساعد الحكومة على تتفيذ مشاريع إستراتيجية دون الاتكال

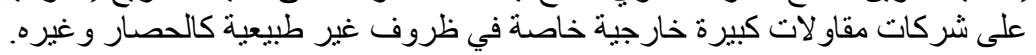

وقد تركت التجربة أثرا جيدا لدى الجهات الرسمية في الحكومة وعلى رأسها اللجنة العليا للمناقصات بالثقة

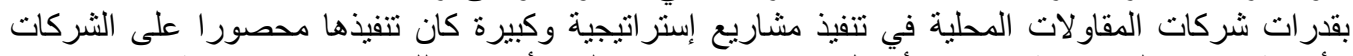

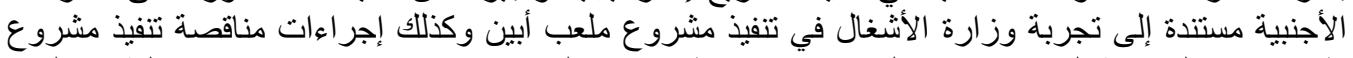

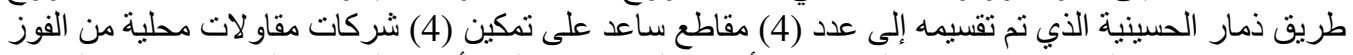

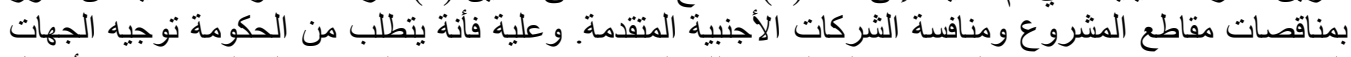

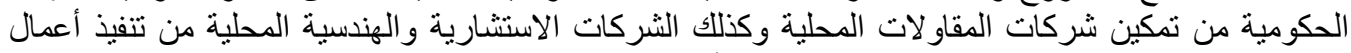

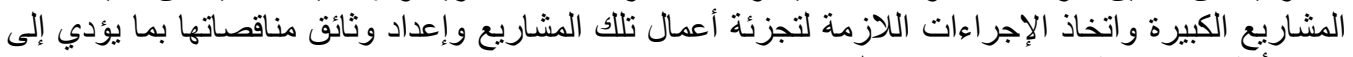

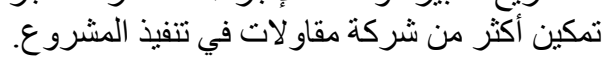

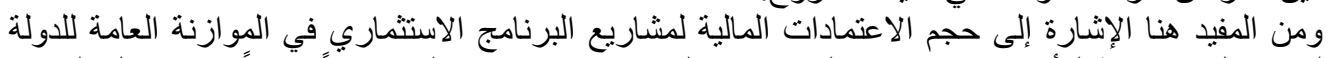

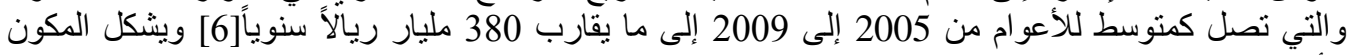
الأجنبي منها نسبة 20\% إلى 30 \% \% و والرسم البياني (1) و الجدول الملحق يعطي مقارنة بين المعتمد السنوي

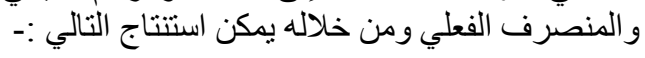

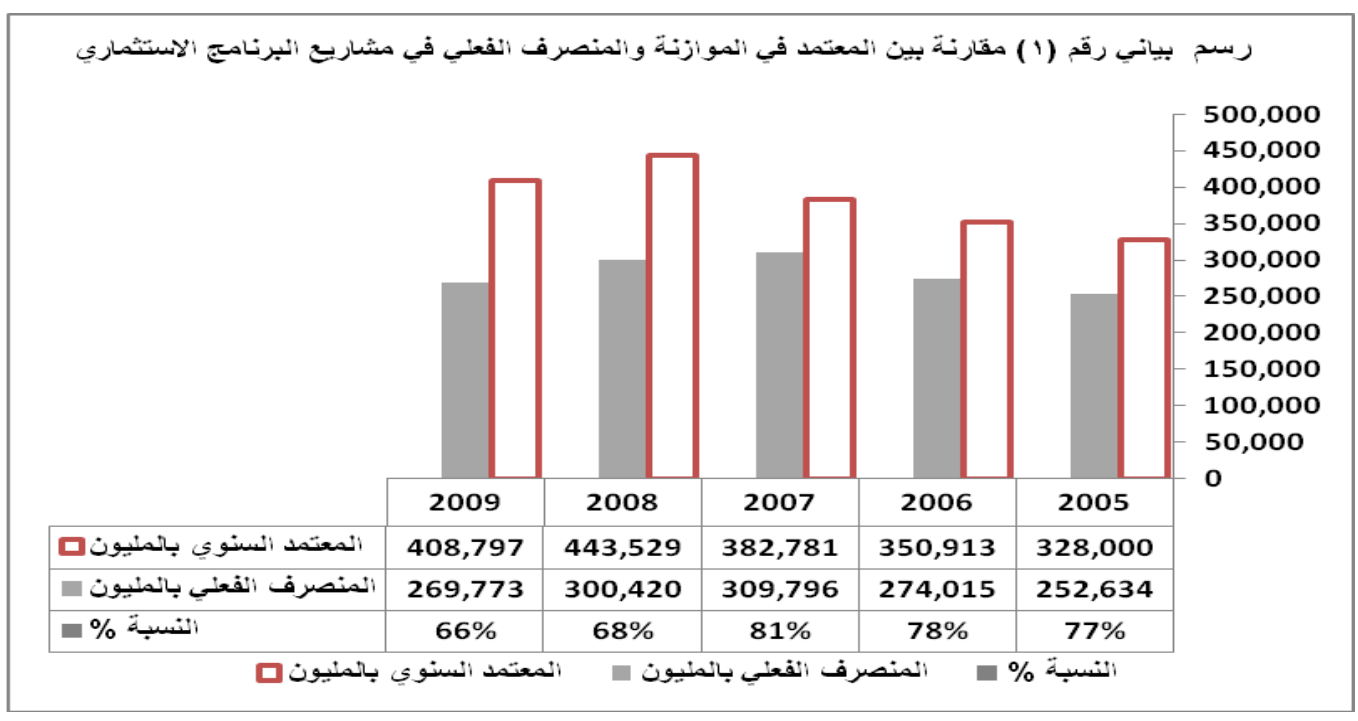


نسبة المنصرف الفعلي تتر اوح ما بين 66\% إلى 81\% وبمتوسط 74\% من المعتمد السنوي، مما يثير

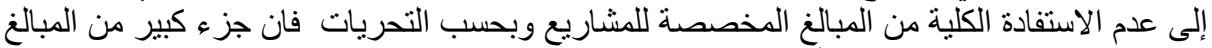

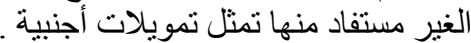

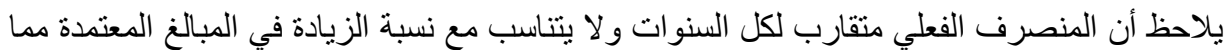

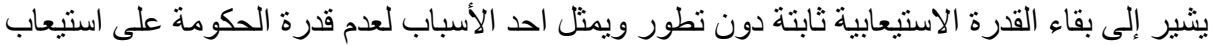

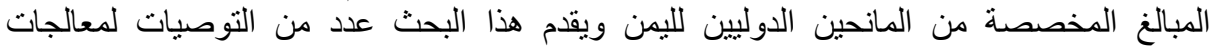

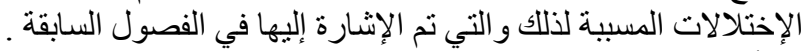

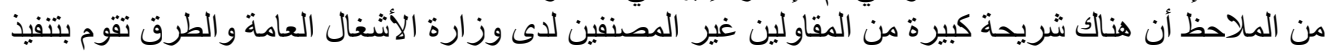

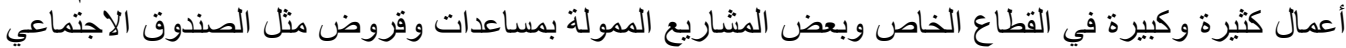

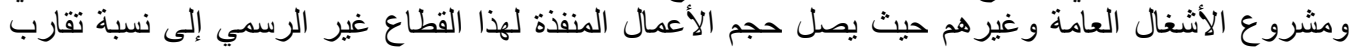

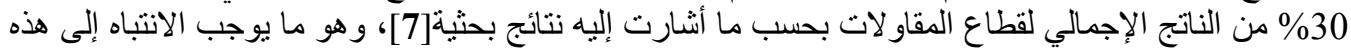

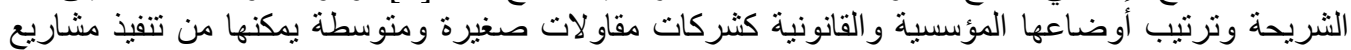

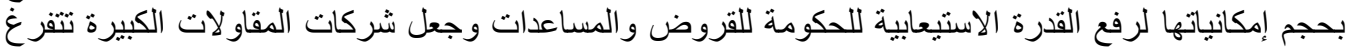
للمشاريع الكبيرة والإنها لرفعر التيجية.

\section{5- الخلاصة والتوصيات}

بينت هذه الدراسة وجود أوجه قصور في قطاع المقاولات احد اهم عناصر صناعة البناء والتشييد في اليمن،

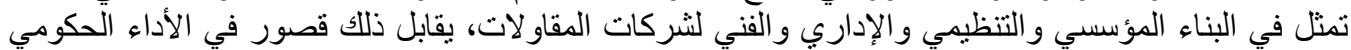

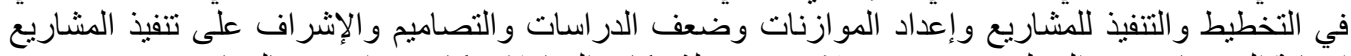

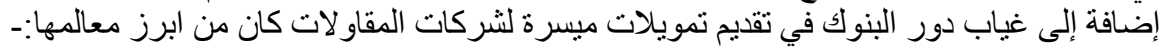

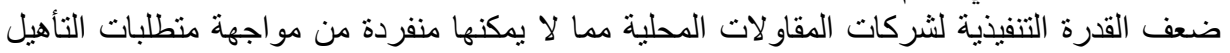

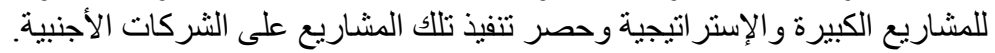

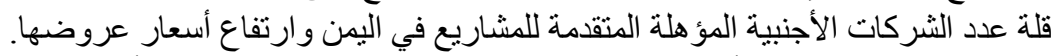

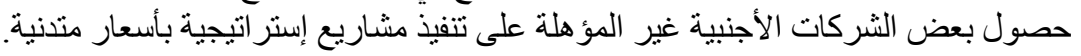
طول فترات تنفيذ المشاريع وتعثر عدد كبير منها. وبناء عليه كانت إحدى أهم النتائج السلبية عدم الاستفادة المثلى من القروض والمنح المخصصة لليمن من المانحين وبالتالي إعاقة تنفيذ خطط التهاء التنمية.

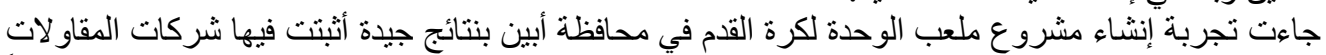

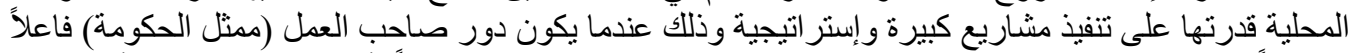

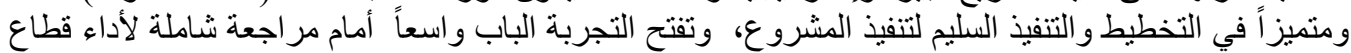

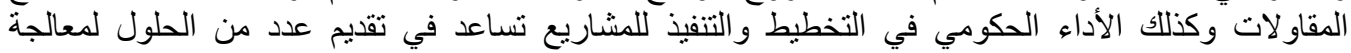

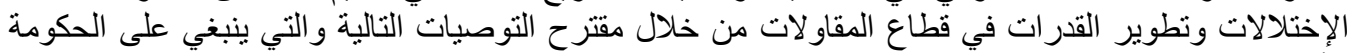

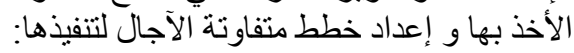

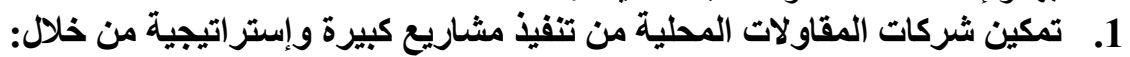

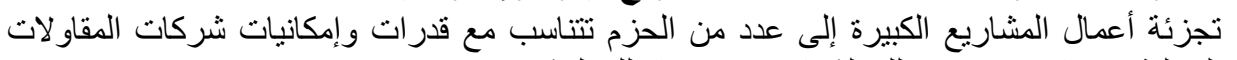

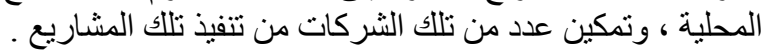

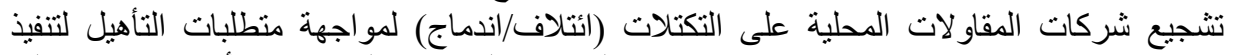

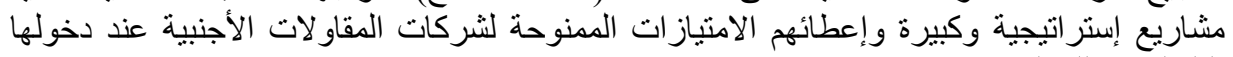

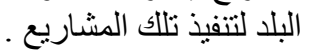
إعطاء امتياز ات لشركات المقاولات الأجنبية التي تأتلف مع شركات المقات المقاو لات المحلية لتنفيذ مشاريع

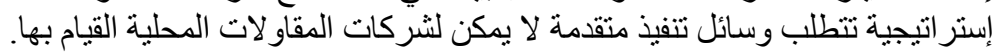

2. رفع القدرات التتفيذية لشركات المقاولات المحلية

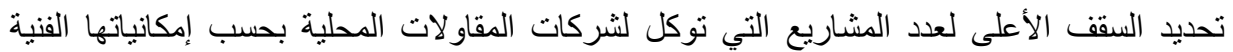
و المادية بما يمنع بعض الشركات الكبيرة من احتكار تتفيذ المشاريع على حساب الثركات الثات الأخرى . 
تقديم التسهيلات اللازمة لشركات المقاولات الصغيرة والمتوسطة لتصحيح أوضاعها المؤسسية

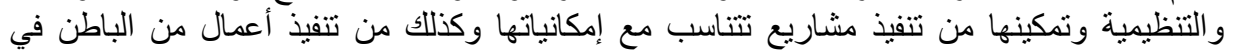

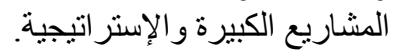

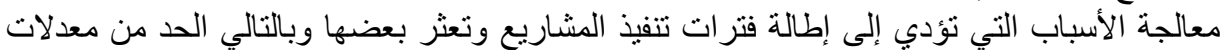

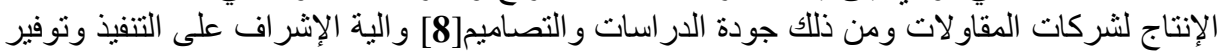

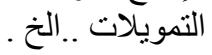

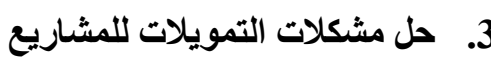

تخصيص اعتمادات مالية كافية في الموازنات المات السنوية بما يتناسب مع الفترة التعاقدية لتنفيذ المشاريع

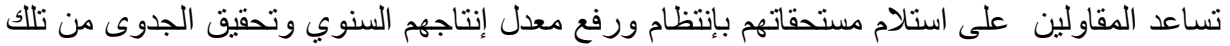
المشاريع. تشجيع البنوك المحلية على توفير التمويلات اللازمة لشركات المقاولات لتنفيذ المشاريع وعمل آلية

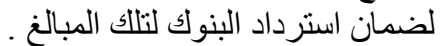

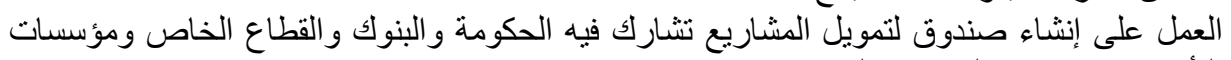
التأمينات وصناديق التقاعد ...الخ.

\section{4. تصحيح البناء المؤسسي والتنظيمي لقطاع المقاولات}

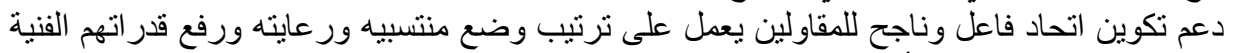

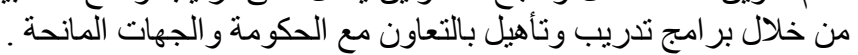

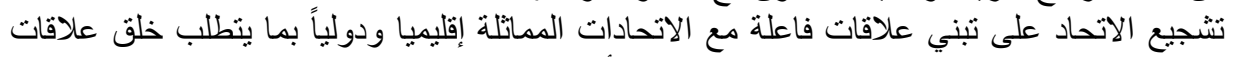

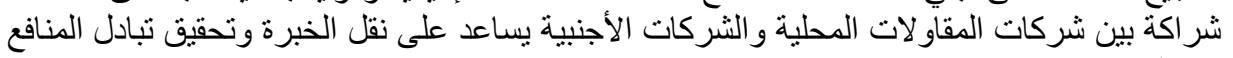
بين الثركاء.

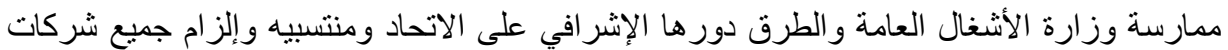

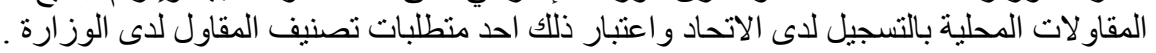

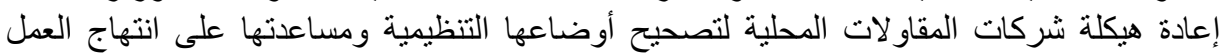
المؤسسي وتخليها عن الأسلوب التقليدي في الإدارة وحصر مركزية التهية القرار بيد ماللك الثركة.

5. إكمال التشريعات القانونية والفنية التي تساعد قطاع المقاولات على النمو والتطور

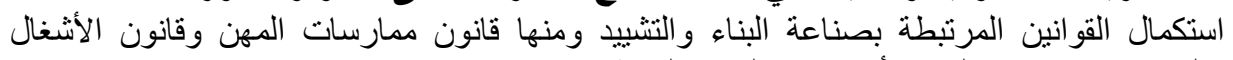

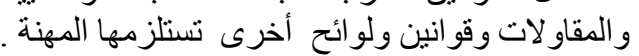

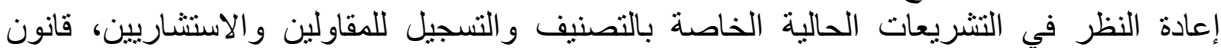

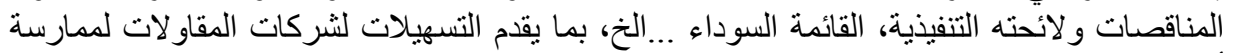

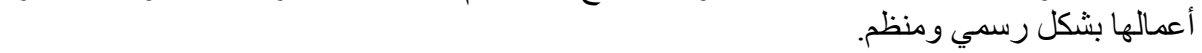
إعداد كود البناء و المواصفات ولئات الفنية الوطنية والأدلة الإرشادية لأعمال التصاميم والإشراف على تنفيذ

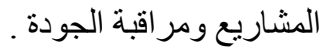

\section{6. بناء القدرات لمنتسبي قطاع البناء والتشييد}

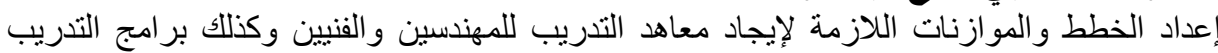

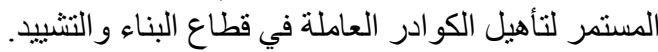

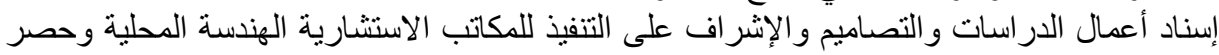

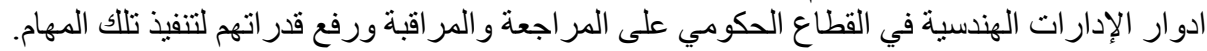

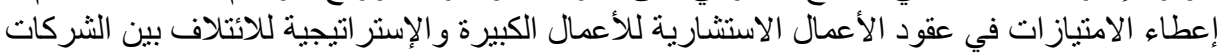

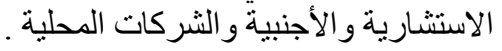


[1] تقرير عن قطاع البناء والتشييد، مجلة الاستثمار، مؤسسة المستثر للصحافة بالتسيق مع الهيئة العامة

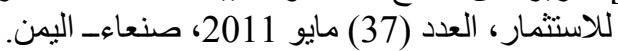

[2] Sultan Basel and Kajewski Stephen, "Local Problems in the Construction Industry of Yemen", Proceedings of International Symposium on Globalization and Construction, W107 Construction in Developing Economics, November 17-19, 2004, Bankok, Thiland.

[3] International Consultants and Technocrats Pvt. Ltd, "Consultancy Services for Assessment of Construction Industry Developments Needs in Yemen", Final Report. New Delhi- India, January, 2011.

[4] وزارة الثئون القانونية، "قانون المناقصات والمزايدات والمخازن الحكومية ولائحته التنفيذية"،الطبعة الثنانة، مارس 2010، صنعاءـ اليمن.

[5] The World Bank "Standard Prequalification Document for Procurement of Works, August 2006, http://www.worldbank.org.

$$
\text { [6] وزارة المالية "نشرة إحصائية مالية الحكومة"،العدد } 38 \text { ، الربع الر ابع 2009، صنعاءـ اليمن. }
$$

[7] Sultan Basel "The Informal Sector in the Construction Industry of Yemen" The Processing of the Second Engineering Conference, Aden University, 30-29 January 2009, Aden-Yemen.

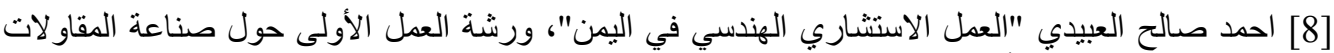

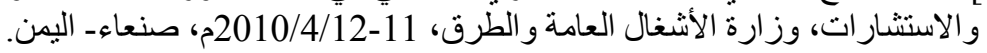

